\title{
Physiotherapist-designed aquatic exercise programme for community-dwelling elders with osteoarthritis of the knee: a Hong Kong pilot study
}

\author{
Mary CK Lau *, Joseph KS Lam, Eva Siu, Carmen SW Fung, Kevin TY Li, Margaret WF Lam
}

\section{A B S T R A C T}

Objectives: To examine the effectiveness and feasibility of a community-based aquatic exercise programme for elders with osteoarthritis of the knee.

Design: Prospective intervention study, with a before-and-after design.

Setting: Community elders.

Participants: Twenty elders aged 65 years or above (mean, 72 years) attending four Elderly Health Centres of the Department of Health who had suffered from osteoarthritis of the knee for at least 3 years and with mild-to-severe knee pain.

Intervention: A 10-week aquatic exercise programme designed and led by physiotherapists.

Main outcome measures: Range of motion and power of extension of the knees, functional reach test, repeated sit-to-stand test, and the Chinese Arthritis Impact Measurement Scales 2.

Results: There was an improvement in the median range of knee flexion from $115^{\circ}$ to $125^{\circ}(\mathrm{P}<0.01)$ and the median strength of the quadriceps from $9 \mathrm{~kg}$ to $21 \mathrm{~kg}(\mathrm{P}<0.001)$. The median score of the $\mathrm{cm} \quad(\mathrm{P}<0.001)$ and the repeated sit-to-stand test from 10 to 14 repetitions $(\mathrm{P}<0.001)$. Also, there was an improvement in the mobility level $(\mathrm{P}<0.01)$, walking and bending ability of the trunk $(\mathrm{P}<0.05)$, levels of pain $(\mathrm{P}<0.01)$ and $\operatorname{mood}(\mathrm{P}<0.01)$, and the total score $(\mathrm{P}<0.01)$ in the Chinese Arthritis Impact Measurement Scales 2.

Conclusions: Physiotherapist-designed aquatic exercise has definite benefits in terms of physical and psychosocial functioning, and should be promoted as one of the strategies to enhance long-term self-management of community elders with knee osteoarthritis.

\section{Hong Kong Med J 2014;20:16-23}

DOI: $10.12809 / \mathrm{hkmj} 133931$

MCK Lau *, MHM, Prof Dip Phty

JKS Lam, Prof Dip Phty

E Siu, MPH, Prof Dip Phty

CSW Fung, MScHC(PT), Prof Dip Phty

KTY Li, MHE\&HP, Prof Dip Phty

MWF Lam, Prof Dip Phty

Shatin VHT Office, Elderly Health Service, Department of Health, Room 326, Shatin Government Offices, 1 Sheung Wo Che Road, Shatin, Hong Kong

* Corresponding author: mary_lau@dh.gov.hk

New knowledge added by this study

- This physiotherapist-designed aquatic exercise (PDAE) programme significantly improves knee functions, symptoms, and psycho-social functioning of the Hong Kong Chinese knee osteoarthritis (OA) sufferers.

- The PDAE programme was effective and feasible in community settings.

Implications for clinical practice or policy

- This study showed that OA knee sufferers can improve in terms of knee symptoms and functioning by means of the PDAE programme used in a community setting.

- The findings support the application of PDAE programme as a form of long-term self-management for OA knee.

\section{Introduction}

Osteoarthritis of the knee (OA knee) is a chronic painful and disabling condition affecting elderly persons worldwide. Among all lower limb joints affected by OA, affliction of the knee is particularly common among the Hong Kong Chinese. A local survey on persons aged 50 years and above revealed that among men, $17 \%$ and $7 \%$ had persistent knee pain and a confirmed diagnosis of OA knee, respectively; the prevalence rates in women were higher, being $24 \%$ and $13 \%$, respectively. ${ }^{1}$

Elderly Health Centres (EHCs) of the Department of Health provide comprehensive primary health care for persons aged 65 years and above. Among attendees of EHCs, OA knee contributes to approximately one third of all physiotherapy referrals. $^{2}$

Physiotherapy in the form of an exercise 
prescription (eg hydrotherapy), other treatment modalities (eg heat therapy, transcutaneous electrical nerve stimulation), as well as the prescription of mobility aids for improving ambulation are examples of recommended non-pharmacological therapies for the OA. These are in addition to patient education and self-management programmes. ${ }^{3}$ There are many studies documenting the efficacy and effectiveness of aquatic exercises (or hydrotherapy programmes) for reducing pain and improving function in patients with OA or rheumatoid arthritis. ${ }^{4-8}$ When one exercises in water, the buoyancy of water decreases loading on lower limb joints. On the other hand, the hydrodynamic resistance and turbulence helps to strengthen muscles and increase proprioception and balance. Hydrostatic pressure also helps to control oedema in the immersed body parts.

This study aimed to examine the effectiveness and feasibility of a community-based aquatic exercise programme for elders with OA knee. The programme, a physiotherapist-designed aquatic exercise (PDAE), was developed by the physiotherapists of the Elderly Health Service (EHS) of the Department of Health.

\section{Methods}

\section{Subjects}

Subjects were recruited by convenience sampling of the elders aged 65 years and above attending any one of the four EHCs in Kowloon, Hong Kong.

\section{Inclusion and exclusion criteria}

Elders who were recruited had to have a clinical diagnosis of OA knee made by EHC doctors, knee pain for at least 3 years, and a self-perceived pain level of at least 'mild' in the affected knee joint(s) during the preceding 1 month.

Unstable heart disease, hypertension, or any other medical contra-indication to mild-tomoderate physical activity were grounds for exclusion. Other exclusion criteria were physical barriers to exercising in water, such as marked postural deformity, blindness, or deafness; severe cognitive impairment; depression not responding to treatment; neurological diseases like Parkinson's disease and stroke; and inability to walk independently. Subjects who had already received active interventions for OA knee during the preceding 2 months or who had scheduled knee operations in the following 6 months were also excluded.

\section{Interventions}

The PDAE consisted of individual and group exercises (Table 1), and was delivered twice a week for 10 weeks in a public indoor swimming pool by registered physiotherapists of the EHS.

All subjects attended a health educational seminar on OA knee and the PDAE before the

\section{由物理治療師為膝關節炎社區老人患者設計的 水中運動班：香港先導研究 \\ 劉昭君、林建成、邵伊華、馮仕為、李統宇、林華鳳 \\ 目的：探討為患有膝關節炎的社區老人開展的水中運動班的效用和可 行性。 \\ 設計：前瞻性介入研究前與後的對比。 \\ 安排 : 社區老人。}

參與者：20名65歲或以上 (平均72歲) 衞生署轄下四個長者健康中心 的會員, 並患有輕度至嚴重膝關節痛至少三年的長者。

介入：由物理治療師設計及帶領，維期 10 週的水中運動班。

主要結果測量 : 膝關節的活動幅度和伸展肌力、功能性伸展測試、反 覆坐立測試、和關節炎衝擊測量表2（中文版）（CAIMS 2）。

結果：參加水中運動班後, 參與者的膝關節屈曲角度從中位數 $115^{\circ}$ 提高至 $125^{\circ}(\mathrm{P}<0.01)$, 而股四頭肌的力量亦從中位數 $9 \mathrm{~kg}$ 增加 至 $21 \mathrm{~kg}(\mathrm{P}<0.001)$ 。功能性伸取測試的中位數從 $20 \mathrm{~cm}$ 增加至 $28 \mathrm{~cm}(\mathrm{P}<0.001)$, 重複坐企測試亦從 10 次上升至 14 次 $(\mathrm{P}<0.001)$ 。 按CAIMS 2, 以下各項均有改善: 能動度 $(\mathrm{P}<0.01)$ 、步行和身軀彎 曲的能力 $(\mathrm{P}<0.05)$ 、疼痛程度 $(\mathrm{P}<0.01)$ 、情緒 $(\mathrm{P}<0.01)$ 和總 分數 $(\mathrm{P}<0.01)$ 。

結論：由物理治療師設計的水中運動, 對膝關節炎患者的身體和社會 心理功能方面絕對有幫助, 建議可把這水中運動班推廣成為加強社區 膝關節炎年長患者自我護理的其中一個策略。

programme. This addressed the aetiology of OA knee, advice on joint care, skills about coping with daily living and self-help tips on symptomatic relief, a rundown of the programme, and the preparation required before undertaking the aquatic exercises.

\section{Measurements}

\section{Characteristics of subjects}

Measurements were carried out in the week preceding and then following the intervention. Demographic and co-morbidity data, including the body mass index (BMI), were collected at baseline. The history of knee pain and its management, selfreported levels of involvement in household work and exercise habits, and details about each subject's living environment were also documented.

\section{Outcome measures}

The outcome measures were:

(1) Self-reported changes in the use of analgesics (type and frequency of use).

(2) Changes in functional status, intensity and pattern of pain, social activity, and level of tension and mood, as measured by the Chinese Arthritis Impact Measurement Scales 2 (CAIMS 2). The CAIMS 2 has been validated on Chinese- 
TABLE I. Details of the physiotherapist-designed aquatic exercise (PDAE) programme

\begin{tabular}{lcc}
\hline Content of PDAE & Time (mins) & Equipment \\
\hline Warm-up on land and in water & 10 & 3 \\
Stepping with arm movement in water & $\sim 1.5$ & - \\
Rest by slow stepping & 3 & Float on waist \\
Alternate hip and knee flexion and extension & 3 & Floats on waist and ankles \\
Bilateral hip abduction and adduction & 3 & Floats on waist and ankles \\
Bilateral hip and knee flexion and extension & $\sim 1.5$ & - \\
Rest by slow stepping & 3 & - \\
Semi-squatting with arm movement in water & 12 & - \\
Group exercise by stepping and gentle jumping in multiple direction & 10 & - \\
Cool down in water & & - \\
\hline
\end{tabular}

speaking patients with arthritis ${ }^{9}$ (Table 2). Thirty relevant items were extracted using CAIMS 2 in the current study, and dealt with mobility, lower limb functions, arthritis pain, and psychosocial status.

(3) Functional exercise capacity was measured by the 6-minute walk test, which measures the maximum distance walked along a 50-metre indoor course in 6 minutes. ${ }^{10}$ Learning effects were minimised by testing each subject once in the pre- and post-test, respectively and by a 3-month period between the tests.

(4) Lower limb strength and function were measured using the dynamometer test of the Nicholas Manual Muscle Tester (NMMT) and the 30-second repeated sit-to-stand test. The NMMT measures isometric quadriceps muscle strength at $30^{\circ}$ of knee flexion. The 30 -second repeated sit-to-stand test entails counting the number of completed repetitions by the subject in 30 seconds, and reflects composite functional strength contributed by extension of the back and legs.

(5) Standing balance was measured by the functional reach test (FRT), which measures the maximum displacement in horizontal distance that the subjects can reach when they stand still. Scores of less than 6 inches $(15.2 \mathrm{~cm})$ indicate limited functional balance, 6 to 10 inches indicate a moderate fall risk, and that of more than 10 inches $(25.4 \mathrm{~cm})$ indicate less fall risk. ${ }^{11}$

(6) The range of motion ( $\mathrm{ROM}$ ) of the knee joints was measured by a goniometer with the subject in a lying position. The range is one of the mediators for the improvement in overall knee function.

\section{Programme feasibility}

The feasibility of running the PDAE programme in the community was assessed as follows:

(a) Difficulties encountered and subjects' concerns during the recruitment;

(b) Attendance during programme implementation and reasons of absence;

(c) Observation of subjects' performance during the PDAE programme; and

(d) Post-study programme evaluation including subjects' satisfaction and their opinion on future service planning.

\section{Statistical methods}

Analyses were performed using the Statistical Package for the Social Sciences (Windows version 10.0; SPSS Inc, Chicago [IL], US). Differences in range of knee movement, quadriceps strength, FRT, repeated sit-to-stand test, 6-minute walk test, and CAIMS 2 scores before and after the PDAE were tested by the Wilcoxon signed rank test, while the difference in the use of analgesic medications for knee pain was tested by McNemar's test.

To detect a change of $20 \%$ in the pain and physical functioning scales of CAIMS 2 with an $\alpha$ level of 0.05 and $80 \%$ power, a sample size of 18 was necessary according to the computer equation for the Wilcoxon signed rank test. To allow for a dropout rate of $20 \%, 22$ subjects were recruited.

\section{Results}

\section{Subject characteristics}

There were 22 subjects, of whom 20 (15 female and 5 male) completed the PDAE programme. Two withdrew from the study-one due to personal and adjustment problems to water temperature, while the other did not attend the post-programme assessment. The mean ( \pm standard deviation) age of the subjects was $72 \pm 2$ years. In all, $35 \%$ of them were illiterate and $50 \%$ had had a primary school education (Table 3). Apart from OA of the knee, $65 \%$ of them had other musculoskeletal problems. Moreover, $65 \%$ of the subjects lived in public housing and the rest in private housing. All of them were 
TABLE 2. The selected items for physiotherapist-designed aquatic exercise assessment out of the original Chinese Arthritis Impact Measurement Scales 2 (CAIMS 2) questionnaire ${ }^{9}$

\begin{tabular}{|c|c|c|}
\hline No. & Question in CAIMS 2 & Selected items in the study \\
\hline & Questions refer to mobility level & \\
\hline 1 & How often were you physically able to drive a car or use transportation? & $\checkmark$ \\
\hline 2 & How often were you out of the house for at least part of the day? & $\checkmark$ \\
\hline 3 & How often were you able to do errands in the neighbourhood? & $\checkmark$ \\
\hline 4 & How often did someone have to assist you to get around outside your home? & $\checkmark$ \\
\hline \multirow[t]{2}{*}{5} & How often were you in a bed or in a chair for most of the day? & $\checkmark$ \\
\hline & Questions refer to walking and bending. During the past month... & \\
\hline 6 & $\begin{array}{l}\text { Did you have trouble doing vigorous activities such as running, lifting heavy objects, or participating } \\
\text { in strenuous sports? }\end{array}$ & $\checkmark$ \\
\hline 7 & Did you have trouble either walking several blocks or climbing several flights of stairs? & $\checkmark$ \\
\hline 8 & Did you have trouble bending, lifting, or stooping? & $\checkmark$ \\
\hline 9 & Did you have trouble either walking one block or climbing a flight of stairs? & $\checkmark$ \\
\hline 10 & Were you unable to walk unless assisted by another person or by a cane, crutches, or walker? & $\checkmark$ \\
\hline $11-16$ & Questions refer to hand and finger function & $x$ \\
\hline $17-21$ & Questions refer to arm function & $x$ \\
\hline $22-26$ & Questions refer to self-care tasks & $x$ \\
\hline \multirow[t]{2}{*}{ 27-30 } & Questions refer to household tasks & $x$ \\
\hline & Questions refer to social activity & \\
\hline 31 & How often did you get together with friends or relatives? & $\checkmark$ \\
\hline 32 & How often did you have friends or relatives over to your home? & $\checkmark$ \\
\hline 33 & How often did you visit friends or relatives at their homes? & $\checkmark$ \\
\hline 34 & How often were you on telephone with close friends? & $\checkmark$ \\
\hline 35 & How often did you go to a meeting of a church, club, team, or other group? & $\checkmark$ \\
\hline \multirow[t]{2}{*}{$36-39$} & Questions refer to support from family and friends & $x$ \\
\hline & Questions refer to arthritis pain. During the past month... & \\
\hline 40 & How would you describe the arthritis pain you usually had? & $\checkmark$ \\
\hline 41 & How often did you have severe pain from your arthritis? & $\checkmark$ \\
\hline 42 & How often did you have pain in two or more joints at the same time? & $\checkmark$ \\
\hline 43 & How often did your morning stiffness last more than 1 hour from the time you woke up? & $\checkmark$ \\
\hline 44 & How often did your pain make it difficult for your sleep? & $\checkmark$ \\
\hline \multirow[t]{2}{*}{$45-49$} & Questions refer to work & $x$ \\
\hline & Questions refer to level of tension. During the past month... & \\
\hline 50 & How often have you felt tense or high strung? & $\checkmark$ \\
\hline 51 & How often have you been bothered by nervousness or your nerves? & $\checkmark$ \\
\hline 52 & How often were you able to relax without difficulty? & $\checkmark$ \\
\hline 53 & How often have you felt relaxed and free of tension? & $\checkmark$ \\
\hline \multirow[t]{2}{*}{54} & How often have you felt calm or peaceful? & $\checkmark$ \\
\hline & Questions refer to mood. During the past month... & \\
\hline 55 & How often have you enjoyed the things you do? & $\checkmark$ \\
\hline 56 & How often have you been in low or very low spirits? & $\checkmark$ \\
\hline 57 & How often did you feel that nothing turned out the way you wanted it to? & $\checkmark$ \\
\hline 58 & How often did you feel that your arthritis is a burden of others? & $\checkmark$ \\
\hline 59 & How often did you feel so down in the dumps that nothing would cheer you up? & $\checkmark$ \\
\hline
\end{tabular}


involved in managing household chores at moderate (60\%) and light (40\%) intensity levels, and 90\% of them had direct lift access to their homes.

Before participating in PDAE programme, 16 of the subjects had pain in both knees and four in one knee only. Specific causes of the knee pain were not identified in 15 of them. Two subjects had pain in one knee without specific cause but the other knee by trauma. Two subjects had knee pain due to overuse. Another subject had knee pain due to overuse and trauma. The main aggravating factors were climbing stairs, squatting, weather changes, and getting up from a sitting to standing position (Table 3).

Nearly all the subjects (90\%) undertook exercises of different forms and intensity; $94 \%$ claimed to exercise daily, $78 \%$ claimed to exercise 30 to 60 minutes per day, and some (17\%) claimed to exercise for more than 1 hour a day. Reported landbased exercises included walking (60\%), general mobilisation exercise (55\%), and Tai Chi (40\%). Half of the subjects encountered difficulties performing daily activities (brisk walking, single-leg standing, squatting, getting up or standing from squatting, or sitting on a low stool) due to knee problems. Subject demographics and clinical features are described in Table 3.

\section{Body mass index}

There was no significant difference in the subjects' mean BMI before and after the PDAE programme (26.6 vs $26.6 \mathrm{~kg} / \mathrm{m}^{2} ; \mathrm{P}=0.658$ ).

\section{Pain-relieving medications}

Before PDAE, more than half of the subjects used analgesic ointments/patches for self-management of knee pain. Apart from medication, only one subject exercised specifically to relieve pain and stiffness in his knee. Three quarters of the subjects found their self-management slightly effective and $20 \%$ found it moderately effective.

After PDAE, the number of subjects taking pain-relieving medications decreased (19 vs 4; $\mathrm{P}=0.004)$, and the numbers relying on oral analgesics decreased from four to one (Table 4).

\section{Outcomes}

According to observations by physiotherapists, subjects with knee swelling all experienced a decrease (10 vs 0 knees; $\mathrm{P}=0.002$ ). There was also a decrease in the girth of the thigh (measured at $5 \mathrm{~cm}$ above the base of patella in both knees) from a mean of $40 \mathrm{~cm}$ to $39 \mathrm{~cm}(\mathrm{P}<0.001)$, despite a substantial increase of muscle strength (Tables 5 and 6).

Owing to the small sample size and skewed data distribution, medians and the non-parametric Wilcoxon signed rank test were used to compare functional outcomes and CAIMS 2 scores.
The medians of the knee ROM increased from $115^{\circ}$ to $125^{\circ}(\mathrm{P}<0.01)$ after the PDAE, while those for total ROM increased from $120^{\circ}$ to $125^{\circ}$ $(\mathrm{P}<0.05)$. The number of subjects who got endof-range pain at flexion decreased from 16 to 8 $(\mathrm{P}<0.05)$. There was also a marked improvement

TABLE 3. Demographic and clinical characteristics of the sample*

\begin{tabular}{lc}
\hline Characteristic & \% of patients \\
\hline Gender & 75 \\
Female & 25 \\
Male & \\
Education level & 35 \\
Illiterate & 50 \\
Primary school & 5 \\
Form 3 & 5 \\
Form 5 & 5 \\
Matriculated &
\end{tabular}

Side of knee suffering from pain

\begin{tabular}{lrrr} 
Both sides & \multicolumn{2}{c}{80} \\
Left & \multicolumn{2}{c}{10} \\
Right & \multicolumn{2}{c}{10} \\
Area of knee pain & 60 & 65 \\
Anterior & 5 & 10 \\
Posterior & 10 & 5 \\
Medial & 0 & 0 \\
Lateral & 20 & 20 \\
Diffused & & & \\
Cause of knee pain & & 85 & \\
Unknown & & 15 & \\
Overuse & 15 &
\end{tabular}

Aggravating factors

Up/down stairs 65

Squatting 65

Weather change 55

Getting up from sitting to standing $\quad 50$

Up/down slopes $\quad 35$

Standing 35

Walking (level ground) 25

Housework 20

Others 25

Usual type of exercise performed

Walking 60

General mobilisation $\quad 55$

Tai Chi 40

Others

15

* Some of the patients had more than one area of knee pain cause of knee pain, aggravating factor, and usual type of exercise performed 
in the medians for quadriceps strength from 9 $\mathrm{kg}$ to $21 \mathrm{~kg}(\mathrm{P}<0.001)$, FRT from $20 \mathrm{~cm}$ to $28 \mathrm{~cm}$ $(\mathrm{P}<0.001)$, and the repeated sit-to-stand test from 10 to 14 repetitions $(\mathrm{P}<0.001)$. There was a slight improvement in the median for the 6 -minute walk

TABLE 4. Frequency and type of analgesic medication used before and after physiotherapist-designed aquatic exercise (PDAE) programme

\begin{tabular}{lcc}
\hline Analgesic medication & \multicolumn{2}{c}{ No. of patients } \\
\cline { 2 - 3 } & Before PDAE & After PDAE \\
\hline Type & 8 & 2 \\
\hline Ointments & 7 & 1 \\
Patches & 4 & 1 \\
Pills & 0 & 0 \\
Injections & & \\
Frequency (per week) & 14 & 4 \\
1-2 & 3 & 0 \\
$3-5$ & 2 & 0 \\
\hline
\end{tabular}

test (Table 5).

There was a significant improvement in mobility level, walking and bending ability of trunk, levels of pain and mood, as well as the total score as measured by CAIMS 2 (Table 6).

\section{Discussion}

\section{Effectiveness of physiotherapist-designed aquatic exercise programme}

Osteoarthritis is associated with muscle atrophy, reduced muscle strength, and decreased ROM. Studies have shown that strength and ROM of women with arthritis are often 70 to $85 \%$ that of women of similar age without arthritis. ${ }^{12}$ Quadriceps weakness is common among patients with OA knee, which is believed to be due to disuse atrophy, as patients tend to unload the painful extremity. ${ }^{3}$ Osteoarthritis is a common disorder in persons older than 65 years and can significantly affect quality of life. ${ }^{13}$

The goal of the PDAE programme was to improve knee function for the OA-affected knee. In this study, the intervention was associated with a reduction in knee pain, improved strength of

TABLE 5. Functional parameters of the knee before and after physiotherapist-designed aquatic exercise (PDAE) programme

\begin{tabular}{lccc}
\hline \multirow{2}{*}{ Function } & \multicolumn{2}{c}{ Median (interquartile range) } & \multirow{2}{*}{ P value } \\
\cline { 2 - 3 } & Before PDAE & After PDAE & \multirow{2}{*}{0.009} \\
\hline ROM in flexion (degrees) & $115(110-122)$ & $125(115-125)$ & 0.039 \\
Flexion with EOR pain (No. of subjects) & 16 & 8 & 0.969 \\
ROM in extension (degrees) & $0(0-0)$ & $0(-1.25$ to 0$)$ & 0.453 \\
Extension with EOR pain (No. of subjects) & 8 & 5 & 0.012 \\
Total ROM (degrees) & $120(110-120)$ & $125(115-126)$ & $<0.001$ \\
Strength of quadriceps (kg) & $9(5-12)$ & $21(12-25)$ & $<0.001$ \\
Functional reach test (cm) & $20(16-22)$ & $28(24-30)$ & $<0.001$ \\
Repeated sit-to-stand test (No. of repeats) & $10(8-12)$ & $14(13-18)$ & 0.092 \\
6-Minute walk test (m) & $365(306-425)$ & $371(326-404)$ & 0.625 \\
\multicolumn{1}{l}{ Walk with knee pain (No. of subjects) } & 7 & 5 & 0.25 \\
\hline
\end{tabular}

Abbreviations: $\mathrm{ROM}=$ range of motion; $\mathrm{EOR}=$ end of range

TABLE 6. The Chinese Arthritis Impact Measurement Scales 2 (CAIMS 2) scoring before and after physiotherapist-designed aquatic exercise (PDAE) programme

\begin{tabular}{lccc}
\hline \multirow{2}{*}{ Different aspect of CAIMS 2 } & \multicolumn{2}{c}{ Median (interquartile range) score } & \multirow{2}{*}{ P value } \\
\cline { 2 - 3 } & \multicolumn{1}{c}{ Before PDAE } & After PDAE & \\
\hline Mobility level & $0.5(0.1-2.4)$ & $0.0(0.0-0.5)$ & 0.002 \\
Walking and bending ability of trunk & $2.0(0.0-3.9)$ & $0.0(0.0-1.5)$ & 0.032 \\
Social activities & $5.3(4.0-6.5)$ & $5.5(4.5-7.5)$ & 0.243 \\
Level of pain & $2.8(2.0-4.0)$ & $1.5(0.5-2.0)$ & 0.001 \\
Level of tension & $1.5(0.5-2.5)$ & $1.0(0.0-2.5)$ & 0.054 \\
Mood & $1.0(0.1-2.5)$ & $0.0(0.0-0.5)$ & 0.003 \\
\hline Total & $\mathbf{1 4 . 0 ( 9 . 0 - 1 9 . 9 )}$ & $\mathbf{9 . 0 ( 7 . 0 - 1 3 . 0 )}$ & $\mathbf{0 . 0 0 1}$ \\
\hline
\end{tabular}


knee extensors, improved knee ROM, and overall body balance; all of which were confirmed by improvements in the sit-to-stand test.

The advantage of exercising in an aquatic environment is that in comparison to usual weightbearing exercises, water buoyancy decreases stress on the lower limb joints and surrounding muscles, which provides the ideal medium for pain and stiffness relief from arthritis. Turbulence and its dynamic resistance is another property that can strengthen all muscle groups surrounding the knee, and improve proprioception and body balance. ${ }^{5}$

The results of this study were concordant with the mentioned benefits of the multi-direction resistance provided by the water environment, such that PDAE strengthens the quadriceps effectively. The increased muscle strength around affected joints is a clinically important outcome, as muscles provide shock-absorbing capacity and joint stability to help preserve the diseased joint. ${ }^{4}$ The decrease in knee joint girth might be explained by reduced swelling and the proximal lift from muscle bulk of the quadriceps and hamstrings due to improved muscle tone.

Moreover, the turbulence of water not only provides resistance but also a multi-directional balance challenge. The aquatic environment enables subjects with intrinsic fall risk factors to exercise safely in functional positions. In this study, improvements in trunk movement ability were also noted in the CAIMS 2 questionnaire. The above factors may be the main reasons for improvement in functional balance. In this study, the medians of the subjects' FRT test results after PDAE improved from a moderate level of fall risk to a less risky level. This change concurs with Simmons and Hansen's findings, ${ }^{13}$ whereby greater improvement in functional reach occurred in subjects who had exercised in an aquatic environment. Challenges to balance in an aquatic environment appear to improve dynamic standing balance on land. This is further supported by motor learning literature, where learners demonstrated the ability to apply what they had learnt from different practice conditions and/ or movement skills. ${ }^{14}$ Standing balance training, if sufficiently dynamic in nature, may also improve the performance of functional activities that combine elements of dynamic balance and overall mobility. ${ }^{14}$ Overall, the functional movement of the knee reflected by the sit-to-stand test also improved.

The improvements in the mentioned domains of knee function were contributed to by decreased knee pain after the programme. In reference to the self-management of the knee symptoms, subjects mainly used analgesic ointment and patches. Before the PDAE programme, they might not have realised that exercise was an effective means of improving their knee pain and function. The PDAE programme benefits subjects via performance of suitable exercise so that they are less dependent on drugs and hence drug-induced adverse effects can be reduced.

Moreover, the present study showed that PDAE had added benefits on both the physical and psychological aspects of patients with $\mathrm{OA}$ knee. Group interaction and socialisation resulting from the interventions may also have influenced psychological domains positively. ${ }^{13}$ Our results were consistent with findings of other investigators, who noted improvements in clinically active joint function after hydrotherapy but not after a landbased exercise programme. ${ }^{5}$ Although there was a deterioration in the medians of the sub-score of social activities in CAIMS $2(\mathrm{P}=0.243)$, this might have been because the latter questionnaire focused on the frequency of getting in touch with friends or relatives, rather than about social activities resulting from the intervention.

Although nearly all subjects undertook exercise and on a daily basis before the programme, there was ample scope for improvement in the physical domains for their knees. This might suggest that different types of exercise, including aquatic exercise, should be performed as part of any exercise programme. Besides, measures should be introduced to reduce risk factors for OA knee, such as weight control by means of diet, exercise, and education.

\section{Feasibility of physiotherapist-designed aquatic exercise programme}

The observed positive effects and the high (96\%) overall attendance rate showed that the PDAE programme was highly acceptable even for a community-dwelling elderly population. This compares very favourably to an attendance rate of 40 to $55 \%$ usually achieved in exercise programmes for persons with arthritis. ${ }^{15}$ Satisfactory compliance could be because those who joined the programme could be non-swimmers, and the programme was relatively short in duration (10 weeks). Moreover, it was conducted during relatively warm months in a training pool provided with temperature control by radiators (room temperature ranged between $19^{\circ} \mathrm{C}$ and $29^{\circ} \mathrm{C}$ ), resulting in an environment warm enough for elders to exercise. Finally, there was good rapport between the subjects and the physiotherapists. Timely advice, support, and encouragement by the physiotherapists might also encourage the subjects to adhere to the programme schedule. Although these components were not evaluated in the programme, one might speculate that emphasis on these aspects helped attain the high degree of compliance.

During the recruitment period and implementation of the PDAE, no difficulties or adverse effects were encountered. The subjects 
found the exercise intensity of the PDAE suitable (mean rate of perceived exertion $=3.3 \pm 1.3$ ). Also, all the participants were satisfied with the programme and accepted its benefits, particularly as the PDAE was feasible for implementation in public swimming pool within a community setting.

\section{Limitation}

A major limitation of this study was the lack of a control group. Therefore, there was no yardstick for comparing the effects of the PDAE with no intervention. Secondly, comparison of outcome measures before and after PDAE could have been influenced by co-interventions (eg use of massage, improvements in posture during daily activities, performance of other types of muscle-strengthening exercises). Moreover, the subjects recruited from EHCs might well be more motivated and health conscious than others. Thirdly, the outcomes were measured without blinding, such that there was always some measurement bias. Finally, the relatively small sample size and recourse to convenience sampling may have conferred imprecision and bias.

The benefits of aquatic exercise were already well established in other studies. Our study confirmed its effectiveness for OA knee, specifically in a public swimming pool within a community setting. Furthermore, the experience we gained was valuable for the conduct of any future aquatic exercise programme in the community.

\section{Conclusions}

The PDAE showed appreciable benefits in terms of reducing knee pain, and improving knee function, body balance, and the psychosocial health of elders with OA knee, including non-swimmers. Populations with OA knee problems and with or without those related to weight-bearing exercise benefited from aquatic exercise. The results justify continuing investment in aquatic exercise programmes as one of the strategies to enhance long-term selfmanagement for elders with chronic OA knee.

\section{References}

1. The Chinese University of Hong Kong. Osteoarthritis in Hong Kong Chinese-Prevalence, aetiology and prevention [press release]; 2001. Available from: www. cuhk.hk/ipro/010306e.htm. Accessed Sep 2004.

2. Elderly Health Service, Department of Health, Hong Kong. Annual Report 2002.

3. American College of Rheumatology Subcommittee on Osteoarthritis Guidelines. Recommendations for the medical management of osteoarthritis of the hip and knee: 2000 update. Arthritis Rheum 2000;43:1905-15.

4. Foley A, Halbert J, Hewitt T, Crotty M. Does hydrotherapy improve strength and physical function in patients with osteoarthritis - a randomized controlled trial comparing a gym-based and a hydrotherapy-based strengthening program. Ann Rheum Dis 2003;62:1162-7.

5. Geytenbeek J. Evidence for effective hydrotherapy. Physiotherapy 2002;88:514-29.

6. Hall J, Skevington SM, Maddison PJ, Chapman K. A randomized and controlled trial of hydrotherapy in rheumatoid arthritis. Arthritis Care Res 1996;9:20615.

7. Minor MA, Hewett JE, Webel RR, Anderson SK, Kay DR. Efficacy of physical conditioning exercise in patients with rheumatoid arthritis and osteoarthritis. Arthritis Rheum 1989;32:1396-405

8. Wyatt FB, Milam S, Manske RC, Deere R. The effects of aquatic and traditional exercise programs on persons with knee osteoarthritis. J Strength Cond Res 2001;15:33740.

9. Chu EM, Chiu KY, Wong RW, Tong WM, Lau CS. Translation and validation of Arthritis Impact Measurement Scales 2 into Chinese: CAIMS 2. Arthritis Rheum 2004;51:207.

10. Enright PL, McBurnie MA, Bittner V, et al. The 6-min walk test: a quick measure of functional status in elderly adults. Chest 2003;123:387-98.

11. Ducan PW, Studenski S, Chandler J, Prescott B. Functional reach: predictive validity in a sample of elderly male veterans. J Gerontol 1992;47:M93-8.

12. Ekdahl C, Broman G. Muscle strength, endurance, and aerobic capacity in rheumatoid arthritis: a comparative study with healthy subjects. Ann Rheum Dis 1992;51:3540.

13. Simmons V, Hansen PD. Effectiveness of water exercise on postural mobility in the well elderly: an experimental study on balance enhancement. J Gerontol A Biol Sci Med Sci 1996;51:M233-8.

14. Rose DJ, Clark S. Can the control of bodily orientation be significantly improved in a group of older adults with a history of falls? J Am Geriatr Soc 2000;48:275-82.

15. Dexter PA. Joint exercises in elderly persons with symptomatic osteoarthritis of the hip or knee. Performance patterns, medical support patterns, and the relationship between exercising and medical care. Arthritis Care Res 1992;5:36-41. 